\title{
LAS SERIES COMO ELEMENTO DE DIFERENCIACIÓN Y AUTOPUBLICIDAD TELEVISIVA. ANÁLISIS COMPARATIVO DE LAS PROMOCIONES DE “FLASHFORWARD”: EE.UU (ABC) VS. ESPAÑA (CUATRO)
}

\author{
Nuria Costas Fontán \\ (Universidad de Vigo) \\ nuriacostas@uvigo.es \\ Mónica Valderrama Santomé \\ (Universidad de Vigo) \\ santome@uvigo.es
}

\begin{abstract}
Resumen: La amplia oferta de TV shows, obliga a las cadenas de televisión a promocionarlas para darlas a conocer y hacer que destaquen entre la multitud de productos televisivos. "Flashforward" es un caso singular en el panorama televisivo español, ya que fue estrenada en España tan solo 14 días después que en EE.UU. Analizaremos la campaña promocional de los canales americano $(A B C)$ y español (Cuatro) que la han emitido para averiguar en qué medida, las promociones de un mismo producto televisivo, difieren o coinciden, en dos cadenas de televisión de dos países diferentes.
\end{abstract}

Palabras clave: Autopromoción, series de televisión, “"Flashforward”", ABC, Cuatro.

Abstract: The wide range of TV shows, requires TV channels to promote them to circulate them and make them stand out from the crowd of television products. "Flashforward" is a singular case in the television Spanish panorama, since it was released in Spain only 14 days later that in USA. We'll analyze the promotional campaign of the channels ABC (USA) and Cuatro (Spain) that have issued it to quarrel with what measure, the promotions of the same television product differ or coincide, in two television channels of two different countries.

Keywords: Self-promotion, TV shows, "Flashforward", ABC, Cuatro.

\section{INTRODUCCIÓN Y METODOLOGÍA.}

I presente trabajo de investigación tiene como objeto de estudio la autopromoción de las cadenas de televisión ABC (EE.UU) y Cuatro (España). Este trabajo se lleva a cabo mediante un análisis comparativo de las autopromo- 
Las series como elemento de diferenciación y autopublicidad televisiva.

Análisis comparativo de las promociones de "Flashfoward":

EE.UU (ABC) vs. España (Cuatro)

ciones entre ambos canales, tomando como referencia el mismo elemento que, además, constituye el nexo de unión entre los dos canales: la serie de televisión Flashforward que, comenzó a emitirse en el canal de televisión americano ABC en septiembre de 2009, y dos semanas después, se estrenó en España en Cuatro.

El objetivo final de esta investigación es la elaboración de una guía o lista de recomendaciones a tener en cuenta a la hora de elaborar una campaña promocional de una serie de televisión. Basándonos en los ejemplos de promociones de la serie Flashforward, y en sus aciertos y errores, hemos encauzado el estudio con el punto de mira en este objetivo.

La muestra del estudio está compuesta por 36 piezas audiovisuales de los canales ABC y Cuatro del año 2009, divididas en cortinillas de canal (5) y en promociones de la serie (19) y de canal (12).

Al inicio de la investigación se han planteado ciertas premisas cuya veracidad pretende ser cuestionada en las conclusiones obtenidas tras la realización del análisis. Las hipótesis se refieren, por un lado, al estilo autopublicitario que tiene cada cadena y, por otro lado, a la promoción de la misma serie de televisión que han hecho las dos. Exponemos, a continuación, las hipótesis de partida:

1. La autopromoción adquiere una relevancia en aumento en el espacio publicitario de la cadena, llegando a tener la duración de un spot convencional (15", 20", 30"). Las autopromociones de canal cuentan, fundamentalmente, con los rostros conocidos y los contenidos del canal, la misma voz en off, y estilos similares.

2. Dentro de las autopromociones, las cortinillas también van adquiriendo mayor importancia y esfuerzos creativos para integrarlas en los contenidos autopublicitarios. Es el caso de Cuatro, cuyas cortinas poseen ejes temáticos temporales y frases características que se integran en el lenguaje cotidiano (ej. "vamos Rafa", "podemos", "tengo una corazonada").

3. Los estilos de las autopromociones de Cuatro y $A B C$ se diferencian tanto en creatividad, temática, formato... constituyéndose con un estilo propio y diferenciado cada uno.

4. La poca diferencia de tiempo con la que se ha emitido la serie en los dos países reduce las posibilidades de copia de Cuatro, con lo cual, se prevén diferencias notables en las promociones de los dos países, si bien es cierto, que la temática ha de ser la misma.

5. Las promociones de la serie, tanto las de $A B C$ como las de Cuatro, tienen un alto contenido corporativo e identificativo con el canal. Los logotipos, voces en off, etc... de las promos, se pueden relacionar e identificar con la cadena emisora.

6. La creatividad en las promociones de la serie en ambos países va más relacionada con la temática y el guión que con la cadena en sí, pues se 
trata de una serie en la que en el primer episodio se cuenta la historia sobre la que girará la serie, siendo el gancho del que dispone para ser promocionada.

En cuanto a la metodología empleada, en primer lugar, pretendemos construir un marco teórico que englobe el objeto de estudio, la autopromoción en televisión, para luego elaborar el estilo promocional que tienen los dos canales, ABC y Cuatro, partiendo de las características de la autopromoción que abordaremos en la teoría. Finalmente, se lleva a cabo el estudio de caso que ilustrará, comparativamente, la autopromoción de Flashforward en los dos canales seleccionados, para extraer las conclusiones finales sobre sus similitudes y diferencias.

En la elaboración del caso práctico nos hemos valido de un modelo de elaboración propia (realizado con los conocimientos adquiridos en la Licenciatura de Publicidad y Relaciones Públicas y extractos de manuales teóricos) compuesto por una serie de parámetros exactamente iguales, analizados en ambos casos.

\section{LA AUTOPUBLICIDAD EN TELEVISIÓN: LA PROMOCIÓN DE SERIES DE TELEVISIÓN}

En el presente trabajo de investigación se han analizado los elementos de continuidad y autopromociones de los canales de televisión ABC y Cuatro, de EE.UU y España respectivamente, centrándonos específicamente en la promoción del mismo producto televisivo: la serie de televisión "Flashforward", estrenada en ABC (EE.UU) el 24 de septiembre de 2009 y 14 días después, en España en la cadena Cuatro.

Este es un hecho inusual en el terreno de las series de televisión estadounidenses, que suelen emitirse en la televisión española meses después de sus estrenos en Norteamérica (mención aparte requiere el hecho de las descargas por Internet de las series, que pueden conseguirse en España apenas unas horas después de ser emitidas en EE.UU, en V.O.S. ${ }^{71}$ ).

Este producto televisivo fue estrenado con éxito de audiencia en EE.UU así como en España. La cadena ABC registró un $12 \%$ de share (12,5 millones de espectadores) y Cuatro obtuvo un $14,3 \%$ de share (2,7 millones de espectadores), siendo este el estreno de ficción extranjera más visto de la historia de la cadena española.

Mediante el análisis comparativo de las campañas de promoción de una misma serie en dos canales de televisión de diferentes países, estableceremos en qué medida el mismo producto televisivo condiciona las similitudes, y la identidad

\footnotetext{
${ }^{71}$ Versión Original Subtitulada.
} 
Las series como elemento de diferenciación y autopublicidad televisiva.

Análisis comparativo de las promociones de "Flashfoward":

EE.UU (ABC) vs. España (Cuatro)

corporativa de las cadenas, favoreciendo, o no, un estilo propio y diferenciado para cada canal.

\subsection{La Identidad Corporativa de los canales de televisión: los concep tos de identidad e imagen}

A menudo se confunden los términos de identidad e imagen corporativa. La Identidad Corporativa ${ }^{1}$ se refiere a la manifestación física de la marca, que se regula en un complejo Manual de Identidad Corporativa, y que se refleja en el logotipo y las diversas aplicaciones del mismo sobre material de papelería, señaléctica y decoración, vestuario... pero también en todas las "actividades de relaciones públicas que ejecuta la empresa para consolidar una determinada imagen corporativa" (Valderrama Santomé, 2005: 3). Esto se resume en la identidad física y visual que adquiere una marca o empresa.

La I.C. "hace referencia a una serie de valores y atributos con los que la empresa se define, y con los que se presenta a las diferentes audiencias. Es, en sí misma, una decisión estratégica, [...] adaptada a las necesidades y características del mercado al cual se dirige" (González Oñate: 2006: 39). La I.C. gestiona todas las actividades comunicativas dentro de una organización, entre las cuales, la I.C. es la parte visible, y que se mezclan entre las miles de identidades visuales, tratando de ser recordada para la audiencia.

La imagen de una empresa no se puede cambiar con la sola renovación del logotipo, como muchas veces se pretende conseguir. La I.C. se arraiga al consumidor o espectador, con la fuerza y el peso del tiempo, y el cambio del logotipo no consigue borrar tan fácilmente la imagen que ha adquirido una organización para comenzar con una nueva imagen. El canal de proyección de la I.C. de una entidad es la Identidad Visual Corporativa (regulada por unas normas de uso), cuya utilidad es la identificación y diferenciación visual de otras entidades por medio de la comunicación corporativa. La creación y ejecución de la IVC se materializa a través del diseño gráfico, que la plasma físicamente en un soporte. El Manual de Identidad Corporativa es una compilación de las normas de estilo gráficas y visuales de una empresa u organización, confeccionado por el diseño gráfico. La Identidad televisiva, es una concreta manifestación de la I.C., en el específico ámbito televisivo, y dirigida al espectador, y con el fin de ganarle la batalla a la competencia y al mando de la televisión, canalizada a través de los mecanismos de autopromoción y continuidad que, posteriormente trataremos.

Joan Costa (1992: 31-34) establece siete elementos como los que forman la Identidad de una empresa (también aplicables a la Identidad televisiva). Hablamos del nombre o la identidad verbal, el logotipo (la transformación de una identidad verbal a una visual), la simbología gráfica (la capacidad de impacto de un sím-

\footnotetext{
${ }^{1}$ En adelante, I.C.
} 
bolo icónico de identidad es superior a la de un logotipo, porque las imágenes son más fuertes que las palabras), la identidad cromática (el color corporativo se convierte en lenguaje y realiza una función identificadora), la identidad cultural (las manifestaciones públicas de la cultura de empresa), los escenarios de la identidad (interacción de la empresa con sus públicos) y los indicadores objetivos de la identidad (informaciones, cifras, datos cuantificados y comprobables).

\subsection{Una aproximación a la marca: la marca en televisión.}

Se conoce comúnmente como marca, un símbolo registrado legalmente para identificar de manera exclusiva productos comerciales o servicios. Este símbolo puede ser una palabra, una frase, una imagen o un diseño, que suele identificarse por medio de un logotipo. Los elementos gráficos y visuales favorecen la diferenciación de los productos con los competidores y contribuyen a la creación de la Identidad. Ese aspecto diferenciador entre marcas es lo que determina la estructura relacional de la marca, como afirma Semprini (1995: 52), su identidad es el resultado de un sistema de relaciones y oposiciones. Una marca no es más que lo que otras no son. Como explica Aaker (2005: 56), una marca poderosa debe identificarse por una identidad rica y clara [...]. Al contrario de la imagen de marca [...] la identidad de marca es aspiracional y puede implicar que la imagen requiera ser cambiada. En un sentido estricto, la identidad representa lo que la organización aspira a que sea la razón de ser de la marca. Los involucrados con la marca deben ser capaces de articular la identidad de marca y deben protegerla.

A menudo pueden confundirse los términos marca y producto, sobre todo a los ojos de los consumidores, espectadores o receptores en general. La diferencia determinante es la tangibilidad que los separa. Keller (2008: 3) define los productos como cualquier cosa que se ofrece en un mercado para su atención, adquisición, uso o consumo y que puede satisfacer una necesidad o un deseo.

Si consideramos un canal de televisión como una marca, comprobamos como se aplican las características que se han descrito: en un mercado de múltiples ofertas, la diferenciación de la competencia se hace vital para su éxito. Las cadenas ofrecen productos televisivos a sus espectadores que, a su vez, son los que los consumen, pudiendo satisfacer un deseo determinado (ocio, evasión, seguimiento habitual...). El hecho de que un espectador siga de forma habitual un determinado producto televisivo, indica que ha habido algún elemento del mismo que ha sido aprehendido positivamente. "Una marca fuerte es valiosa en la industria del entretenimiento por los sentimientos fervientes que generan los nombres como resultado de experiencias pasadas placenteras" (Keller, 2008: 25).

"[...] En la marca global de un canal de televisión, se van constituyendo de forma progresiva 'pequeñas marcas' que le van configurando una Identidad Global corporativa de la cadena" (González Oñate: 2006: 291). Estas pequeñas marcas son un cúmulo de elementos tales como, las cabeceras de cada programa (siempre diferentes), los rostros conocidos, la forma de promocionarse en los espacios 
124 Las series como elemento de diferenciación y autopublicidad televisiva. Análisis comparativo de las promociones de "Flashfoward":

EE.UU (ABC) vs. España (Cuatro)

publicitarios, las sobreimpresiones que anuncian programas en otros programas o la adaptación de continuidad: cortinillas o la mosca, y productos audiovisuales por los que se apuesta.

El reconocimiento de marca que da una identidad televisiva diferenciada es inmediato, pues cada elemento de los mencionados nos permite conocer en qué canal estamos en ese momento. Al igual que Chris Barker (1999: 28), que explica que "el mejor modo de entender la identidad es describiéndola como un entramado de pautas de discurso que forman una red sin centro y no como una serie de atributos poseídos por un yo nuclear unificado" nos inclinamos a afirmar que cada "gesto" de la identidad nos permite vislumbrar en qué número de mi mando a distancia estoy.

\subsection{La promoción de contenidos: la continuidad televisiva}

Los elementos de continuidad "suponen una transición paliativa de la fractura programática, gancho, y un recordatorio sobre la oferta televisiva; una apelación seductora al destinatario y a la coherencia discursiva" (Barroso García, 2002: 525).

Cristina González Oñate (2006: 355) propone una definición de la continuidad televisiva como "el conjunto de manifestaciones audiovisuales, en materia de expresión de la Identidad corporativa, que una cadena de televisión realiza con el fin de servir de nexo homogéneo para interconectar, de manera discursiva, su producto (programación) con la proyección de su Imagen corporativa de cara a la audiencia". Los componentes de la continuidad televisiva abarcan, en general, todos los elementos que identificamos como integrantes de la I.C. de la cadena. Debido a la función individualizadora de un canal de televisión (que busca diferenciarse de su competencia), los límites estéticos y de contenido responden al copy o al Manual de Imagen Corporativa de la cadena (Barroso García, 2002: 525).

\section{EL ESTILO AUTOPROMOCIONAL DE ABC Y CUATRO}

Para la elaboración del estilo autopromoción de los dos canales emisores de la serie "Flashforward" se ha realizado un análisis de una muestra seleccionada de diversas piezas autopromocionales (cortinillas, spots,...) de las cadenas del año 2009. Tras el análisis de los diferentes elementos que forman las campañas de promoción de contenidos y autopromoción hemos establecido el estilo promocional de $A B C$ y Cuatro.

\subsection{La autopromoción en $A B C$}

En la cadena norteamericana se han detectado diversas especificidades promocionales que marcan las diferencias con respecto al canal español. En primer lugar, las cortinillas que dan paso al bloque publicitario (y lo cierran) son piezas 
en las que únicamente se realiza una animación del logotipo de la cadena. No se incluyen otros elementos como rostros conocidos o los logotipos de los programas. La duración de las cortinillas es muy breve, como en la gran mayoría de canales.

En el análisis hemos clasificado en tres grupos las sobreimpresiones ${ }^{2}$ que pueden aparecer en el transcurso de una serie de televisión. Estos grupos son:

1. Sobreimpresiones animadas, que proporcionan dinamismo y captan me jor la atención del espectador al incluir movimiento.

2. Sobreimpresiones estáticas, cuya función reside en mostrar la informa ción de fecha y hora de emisión del contenido promocionado, sin más animación que la del logotipo de la cadena "recogiendo" el crawll3.

3. Sobreimpresiones duraderas, fijas en la pantalla durante cerca de un minuto.

Las sobreimpresiones de $A B C$ utilizan los logotipos originales de cada serie promocionada combinados con la I.C. de la cadena. El tamaño que ocupan estos elementos, en relación con la pantalla, es bastante elevado. Se ubican en la posición central-inferior del encuadre y su tamaño favorece que el espectador se percate de la inserción.

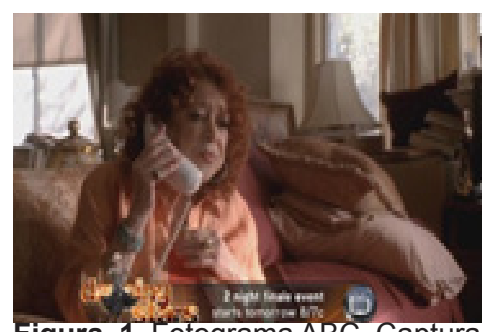

Figura. 1. Fotograma ABC. Captura de pantalla de un episodio de "Desperate Housewives"

Las sintonías que aparecen en las promociones de las series de $A B C$, no pueden ser consideradas como corporativas de la cadena, puesto que van acorde con la temática y tono que transmite cada spot. La voz corporativa es la misma en todas las promos del canal, aunque en ocasiones nos cueste identificarla en los diferentes spots. Esto ocurre porque la voz se adapta al tono que la cadena quiere expresar en cada anuncio. Una voz corporativa profunda, como en el caso de $A B C$, sabe transmitir más allá de las palabras para hacer partícipe al espectador de lo que se pretende contar.

Los tipos de promociones que realiza $A B C$ se dividen en dos grupos, principalmente:

1. Promos de fragmentos de escenas de las diversas series de la cadena.

\footnotetext{
${ }^{2}$ Las sobreimpresiones no suelen durar más de cinco segundo y son utilizadas por los canales de televisión para anunciar noticias de última hora o hechos de interés para el telespectador. Además son formas de promocionar contenidos dentro de otros contenidos, fuera del bloque publicitario.

${ }^{3}$ Sobreimpresión.
} 
Las series como elemento de diferenciación y autopublicidad televisiva.

Análisis comparativo de las promociones de "Flashfoward":

EE.UU (ABC) vs. España (Cuatro)

2. Promociones de elaboración propia, creadas con los personajes de las series, que se hallan en un mismo contexto, (un barrio residencial, alusión clara a la serie Desperate Housewives) en el que se cruzan historias de las distintas series con un tono definitivamente cómico.

La realización de una campaña promocional de las series de televisión, contando con la participación de los protagonistas de las mismas resulta un atractivo reclamo para el espectador.

En definitiva, $A B C$ ha combinado dos maneras de promocionar sus series de televisión, y ha realizado una intensa labor promocional de contenidos, involucrando a sus personajes y rostros conocidos, para buscar la complicidad con el espectador.

\subsection{La autopromoción en Cuatro.}

Por otro lado, en el estudio de los elementos de continuidad y promoción de la cadena española Cuatro, se han detectado diversas particularidades. Cuatro es uno de los canales españoles que mayor importancia ha otorgado a su labor autopublicitaria. Los demás canales de televisión generalistas españoles han ido modificando su I.C. con el paso del tiempo, aunque sus elementos de continuidad no siempre han ido acorde con el corporativismo de la marca. No es el caso de Cuatro que, a pesar de su corta existencia, ha mantenido siempre una misma línea estética en su publicidad.

Las cortinillas de Cuatro han sido toda una novedad desde su nacimiento. Cuando lo común era hacer solamente una animación del logotipo, esta cadena introduce a los rostros famosos que la caracterizan, en la pieza. Así, presentadores o actores protagonizan este corto espacio que separa la programación del bloque publicitario.

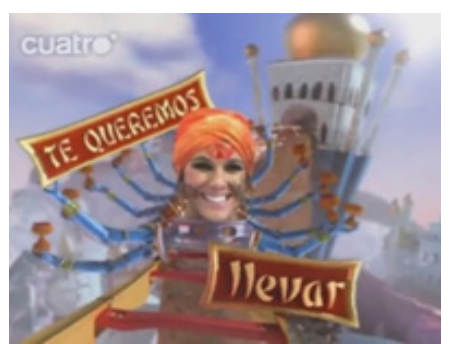

Figura. 1. Fotograma de cortinilla de Cuatro.

Sin embargo, no es esta la única novedad que presentan las cortinillas de Cuatro: la creación por ordenador, de nuevos espacios o realidades, que recuerdan o evocan, a diversos contenidos de la programación habitual. Un claro ejemplo de ello son el grupo de cortinillas de la serie "te queremos". Cuatro ha utilizado el espacio de las cortinillas como herramienta de promoción de contenidos en diversas ocasiones.

En líneas generales, las piezas promocionales de Cuatro contienen un sello distintivo: su alto contenido corporativo, representado por la voz en off, los colores rojo y blanco, la tipografía y el símbolo que representa a la cadena ( ). La utilización de uno o varios de estos elementos depende el contenido argumental de la promo. El patrón más extendido es el de dejar para el final del anuncio la 
inserción del logotipo de la cadena, una sobreimpresión textual y el uso de la voz en off como cierre del mismo. Es habitual que se empleen intertítulos (con la tipografía corporativa) y voz en off como recursos que intensifican las emociones que desea transmitir. Sin embargo, en las promociones corporativas de Cuatro el elemento que posee mayor importancia, por su poder de sugerencia, son las melodías que se emplean como fondo acústico. La elección de las melodías se realiza de tal manera, que se produce una intensificación de las emociones y, además, favorece que el mensaje promocional vea completada su intención.

En cuanto a las sobreimpresiones utilizadas durante la emisión de las series de televisión, éstas pueden situarse tanto en la parte superior, como inferior de la pantalla. No obstante, la posición del crawll determina un uso distinto en cada caso: las sobreimpresiones superiores tienen relación directa con el contenido emitido en ese momento (nombre del programa o capítulo en caso de una serie, aviso de la posibilidad de interacción con la web...) y las sobreimpresiones que aparecen en la posición inferior de la pantalla promocionan otros contenidos: pueden dar información sobre la fecha y hora de emisión de otro programa, avisos de última hora, frases promocionales, etc. Los textos de las sobreimpresiones son escritos con la tipografía y colores corporativos de Cuatro.

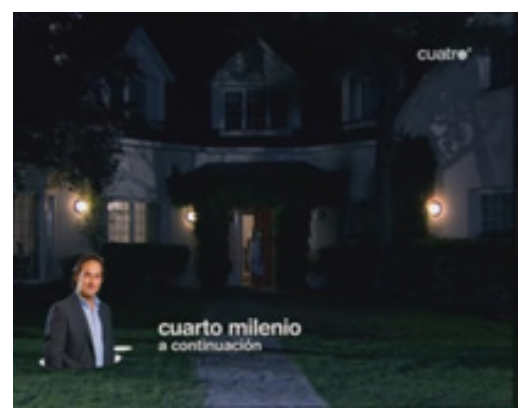

Figura 3. Fotograma Cuatro. Captura de pantalla de un episodio de "Hay alguien ahi".

vez aportada, desaparece de la pantalla.

Son sobreimpresiones en movimiento, las animaciones que anuncian la emisión de un contenido, en las que se incluye una pequeña imagen de un rostro conocido del programa publicitado. Las sobreimpresiones de corta duración hacen referencia directa (ofrecen información sobre el nombre, capítulo, etc.) al programa que se emite en un momento determinado.

Basándonos en las observaciones de un estudio llevado a cabo por Maite Ribés (2006) en el que se realiza un visionado de 28 horas de programación de los canales Telecinco y Cuatro (siendo este último en el que fijamos nuestra atención), y las conclusiones extraídas de este análisis, podemos indicar que:

1. Cuatro innova en los formatos publicitarios. 
128 Las series como elemento de diferenciación y autopublicidad televisiva. Análisis comparativo de las promociones de "Flashfoward":

EE.UU (ABC) vs. España (Cuatro)

2. El spot sigue siendo el formato predominante, aunque están surgiendo nuevas fórmulas que se emplazan tanto en los bloques publicitarios como en los contenidos televisivos.

3. Una fórmula en auge es el mini-programa, de corta duración y producido por los anunciantes. La estructura de estas piezas es: careta de entrada de 7"/ contenido programa / careta de salida de 7".

4. En cada bloque publicitario aparece, al menos, una autopromoción de la cadena.

5. La saturación del medio es evidente: en 28 horas de programación, el cfvespectador recibe más de mil impactos publicitarios, y se emiten más de ochocientos spots.

6. El fenómeno de las autopromociones y su importancia creciente puede ser debido a dos razones: la necesidad de informar al público de su programación ${ }^{4} y$, por otro lado, la necesidad de crear marca televisiva para fidelizar al público.

\section{LA PROMOCIÓN DE "FLASHFORWARD" EN ABC Y CUATRO: SIMILITUDES Y DIFERENCIAS}

La muestra de los spots promocionales de los dos canales de televisión incluía tres tipos diferentes de promos:

1. Promoción del estreno de la serie,

2. Promoción de otra serie (conocida y de éxito) además de "Flashforward",

3. Promoción de la reanudación de la serie tras el parón, especialmente largo, después del período navideño.

Para lograr un análisis más completo hemos incluido en el análisis la promoción de la serie por parte del otro canal de televisión que ha emitido "Flashforward" en España, $A X N^{5}$.

Hemos establecido unos elementos para analizar en cada una de las piezas audiovisuales, que nos permitan constituir una comparación más rigurosa. Los elementos son los siguientes:

1. Realización y contenido: tipos de planos que predominan, movimientos de cámara más relevantes, tipo de transiciones, efectos...

2. Personajes: papel de los protagonistas de las promociones en relación a su personaje en la serie.

\footnotetext{
${ }^{4}$ En la actualidad y, tras muchos años de polémica, los canales de televisión están obligados a hacer públicas sus parrillas televisivas con, al menos, tres días de antelación.

${ }^{5} \mathrm{AXN}$ es un canal temático e internacional de la televisión digital (de pago), propiedad de Sony Pictures Television. Centra sus emisiones en series de televisión, cine y producciones propias.
} 
3. Efectos de sonido y música: características de los efectos sonoros y su correspondencia con el género de acción al que pertenece la serie.

4. Voz en off: la ausencia o presencia de la voz en off, como elemento sonoro explicativo y promocional.

5. Identidad Corporativa Gráfica de la serie y de la cadena.

6. Reclamo visual y poder de sugerencia: elementos que destaquen sobre los demás para atraer la atención del espectador.

Antes de profundizar en las similitudes y diferencias que hemos detectado en las promociones de la serie estadounidense, consideramos necesario hacer una breve referencia al argumento de "Flashforward", debido a las alusiones que haremos a la trama o personajes de la serie en el desarrollo de la comparación de las piezas promocionales.

\subsection{Sinopsis de "Flashforward"}

La serie comienza el 6 de octubre de 2009, día en que todos los habitantes del planeta se desvanecen durante dos minutos y diecisiete segundos, tiempo en el que ven su futuro del 29 de abril de 2010. El protagonista principal de la serie es el agente Mark Benford que, junto con sus compañeros del FBI, son los encargados de resolver el misterio del fenómeno: las causas que lo han producido, quiénes están detrás...El FBI y el entorno personal de cada agente agrupan los personajes principales y secundarios de la serie, cuyas visiones del futuro marcan las historias del presente. Paralelamente a la resolución del caso, cada personaje tiene pendiente la resolución de su propio conflicto futuro.

\subsection{Similitudes entre las promociones de $A B C$ y Cuatro de la serie "Flash forward"}

La principal semejanza apreciable entre las promociones de los dos canales, y que resulta el elemento en común más evidente entre ambos, es la utilización de la misma selección de fragmentos de escenas de la serie. Una serie de planos se repiten en prácticamente todos los anuncios que hemos analizado y presentan la trama principal de la serie. Mostrar este tipo de imágenes permite al espectador conocer el argumento de la serie "Flashforward", sus personajes principales e, incluso, parte de las visiones de los protagonistas. Con esta información, el espectador posee suficientes datos que le hagan sentirse atraído, o no, por el producto televisivo anunciado.

Las escenas que más reiteran en las promos españolas y americanas son, sin duda, las del despertar tras el desvanecimiento de la población mundial, en una situación de auténtico caos y desconcierto sobre lo ocurrido. El argumento o eje temático sobre el que gira cada una de las promociones analizadas es uno 
Las series como elemento de diferenciación y autopublicidad televisiva. Análisis comparativo de las promociones de "Flashfoward":

EE.UU (ABC) vs. España (Cuatro)

de los elementos que muestra a la vez, semejanzas y diferencias entre los spots de los dos canales de televisión. En cuanto a las similitudes, resulta inevitable que, tratándose de la misma serie de televisión, no se redunde en el uso de las mismas escenas, no se dé más importancia a los personajes principales o no se potencien las tramas más significativas. La serie "Flashforward" tiene un guión muy específico y concreto, y menos disperso que otras series de televisión. Por lo tanto, la labor promocional de este producto televisivo está limitada a los aspectos más característicos de la serie y que la diferencian de las demás.

Las líneas temáticas en las que más coinciden las promociones de los dos canales tienen que ver con la presentación argumental de la serie (el desvanecimiento durante dos minutos y diecisiete segundos de la población mundial, en los que cada persona tuvo la visión de su futuro, seis meses después) y los protagonistas. Asimismo, se revelan fragmentos de las visiones de alguno de los personajes principales, adelantando los problemas de cada uno de ellos (trama secundaria de la serie).

A grandes rasgos, existen dos maneras de enfocar la promoción de la serie, apreciables en los dos canales de televisión, $A B C$ y Cuatro: potenciando la acción o, por el contrario, limitando la presencia de los elementos visuales y sonoros que la sugieren. Encontramos promociones con una alta carga de dinamismo, ritmo acelerado y escenas trepidantes, así como promos más relajadas o pausadas. Las dos cadenas de televisión poseen spots promocionales de estas características, si bien es cierto, que los elementos sonoros, aunque sugieren prácticamente lo mismo, varían de un canal a otro.

Cuando se trata de piezas de acción, existe un abundante número de planos y de corta duración, transiciones rápidas entre planos, y melodías de fondo con tintes épicos y de intriga. Por el contrario, las promociones que no contienen tantos rasgos de acción y se centran en tramas de la serie más relajadas, poseen planos de mayor duración y transiciones más lentas, con fundidos a blanco. Las piezas musicales son más melódicas y pausadas.

Sin embargo, existen unos elementos comunes en los dos tipos de promociones de "Flashforward", como son el uso de efectos sonoros que simulan ráfagas y golpes. Las ráfagas son utilizadas de manera que se relacionan con las visiones o flashforwards del futuro (imitando un sonido que el espectador identifique como una visión). Los golpes, generalmente seguidos por un efecto eco, acentúan el carácter intrigante de la serie y son utilizados para acentuar momentos de tensión, creando expectación. Otro de los elementos sonoros que contiene grandes similitudes en las promociones de los dos canales es la música o melodías de fondo. En el análisis de las promos insistimos en el marcado carácter de suspense que sugerían las sintonías musicales utilizadas como fondo acústico.

Las promos de $A B C$ y Cuatro también tienen en común la utilización de intertítulos. Éstos se intercalan entre los diversos planos de los anuncios con textos relacionados con la serie. Los textos tienden a ser palabras o frases cortas, 
relacionadas con el argumento de la serie y con pinceladas de intriga. En los spots previos al estreno de "Flashforward" los intertítulos recurren a presentar las credenciales de la serie, dando a conocer que los creadores de la serie son los mismos que los de otros productos de reconocido éxito como Lost o Batman Begins. Con ello se pretende otorgar cierto prestigio o avalar una buena acogida por parte del público.

Encontramos similitudes en el uso ocasional e intercalado de la voz en off con los diálogos de los personajes. No podemos afirmar el uso generalizado de este recurso, pues no todas las promociones cuentan con él. Sin embargo, cuando ABC y Cuatro utilizan la voz en off lo hacen de una forma muy similar: no ocupa toda la duración del spot, se intercala con los diálogos de los personajes y sugiere intriga en cada caso. Además, la voz en off coincide con la voz corporativa de la cadena en las dos televisiones. Este hecho contribuye a dotar el anuncio de una buena dosis de corporativismo, favoreciendo al espectador la identificación del producto (la serie) con la cadena. En este punto debemos destacar que el uso de la voz en off es considerablemente mayor por parte de la cadena española.

Mencionamos en varias ocasiones en el análisis de las promociones un elemento que se repite en la gran mayoría de los spots (de $A B C$, Cuatro y $A X N$ ): la aparición de un ojo humano del que nace un torbellino de imágenes que se suceden con gran rapidez. Como hemos adelantado en el análisis, este recurso (o parecido) ha sido utilizado previamente en la serie de los mismos creadores de "Flashforward" y emitida también por ABC, "Lost".

Cada una de las temporadas de "Lost" comienza con el plano del ojo del protagonista principal de la serie, abriéndose repentinamente. Teniendo en cuenta que los creadores de las dos series son los mismos, no debemos considerar esto como un hecho aislado o carente de significado. Lo más probable, y que planteamos como una hipótesis, es que se trate de un "guiño" al espectador habitual de "Lost", para ganarse su simpatía hacia "Flashforward".
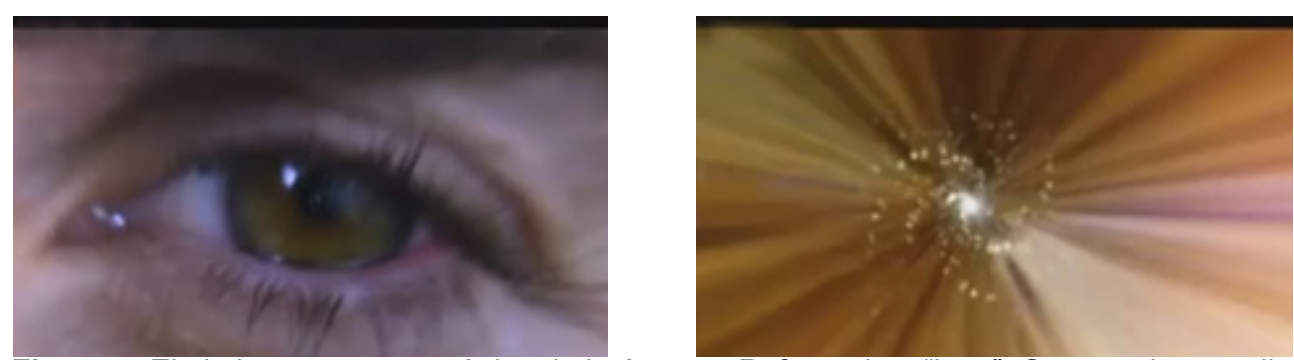

Figura 4. El ojo humano como vórtice de imágenes. Referencia a "Lost". Captura de pantalla de promo de "Flashforward".

Este elemento del ojo humano como vórtice aporta un gran dinamismo a las promociones de "Flashforward". Tras la aparición del ojo se suceden de forma muy rápida una multitud de planos que pertenecen a escenas de la serie. La 
132 Las series como elemento de diferenciación y autopublicidad televisiva. Análisis comparativo de las promociones de "Flashfoward":

EE.UU (ABC) vs. España (Cuatro)

velocidad a la que transcurren imposibilita un reconocimiento por parte del espectador de cada una de las imágenes que han pasado ante sus ojos. Éstas van acompañadas por una música acelerada y vertiginosa que sugiere acción. Este recurso es el que sugiere más acción y ritmo frenético de todos los utilizados en las promociones de la serie, tanto en España como en EE.UU.

Estos aspectos se reflejan en la realización de los spots, permitiendo la identificación de un estilo promocional similar en cada cadena. Los tipos de planos (generalmente planos fijos y de corta duración), de transiciones (rápidas y con fundidos a blanco) y las melodías de fondo que intensifican el ritmo de cada promoción (sea trepidante o relajado), si bien es cierto que no son exactamente iguales en los dos canales, poseen características tan similares que sugieren a los espectadores de los dos continentes sensaciones parecidas.

\subsection{Diferencias entre las promociones de $A B C$ y Cuatro de la serie "Flashforward"}

Una vez concluido el análisis de las piezas promocionales de "Flashforward" en los dos canales de televisión que la han emitido, $A B C$ y Cuatro, encontramos dos grandes diferencias que engloban todos los puntos en los que difieren las promos en ambos países: la utilización de los elementos corporativos y las voces en off de las cadenas, una masculina y otra femenina, así como el uso y la mayor presencia de una sobre otra.

\subsubsection{Elementos corporativos}

La autopublicidad de una serie de televisión adquiere, indudablemente, un contenido corporativo del canal emisor en alza. Si bien en un principio las promos fueron creadas como un recurso de los canales de televisión para dar a conocer su programación a los espectadores, hoy en día han aumentado sus funciones, incluyendo la de proyectar la I.C. de la cadena. Tanto es así, que en la nueva Ley del Sector Audiovisual se contempla que la autopromoción de los canales de televisión puede ocupar hasta un $25 \%$ del bloque publicitario, siendo éste no superior a los veinte minutos por hora.

Diferenciamos en el análisis dos aspectos en referencia a la I.C. que aparecen en los anuncios: por un lado la de la cadena de televisión que emite las piezas y, por otro, la de la serie de televisión. Empecemos por el de la serie. Como la mayoría de los productos televisivos actuales, "Flashforward" tiene una Identidad Corporativa Gráfica, original e inédita. Esa I.C. es la que ha utilizado la cadena norteamericana $A B C$ en sus spots promocionales. En España, Cuatro ha utilizado una versión adaptada a su propia I.C. del logotipo original de la serie. Con esto se consigue una mayor identificación de la misma con la cadena. A continuación exponemos el logotipo original de la serie y el modificado y utilizado por Cuatro. 


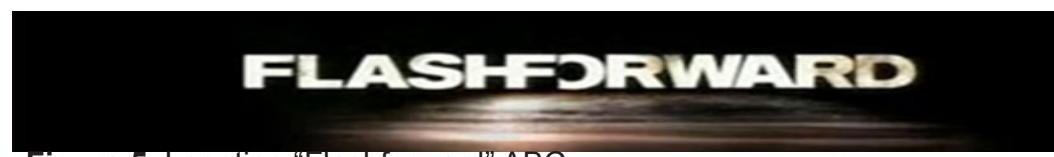

Figura 5. Logotipo "Flashforward" ABC.

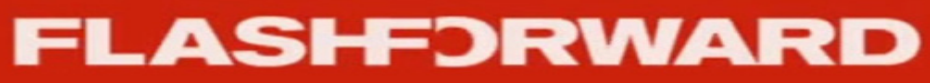

Figura 6. Logotipo "Flashforward" Cuatro.

Podemos observar que Cuatro mantuvo la tipografía corporativa pero modificó la combinación de colores: mientras que el logo original estaba realizado en contratipo ${ }^{6}$ con un relleno salpicado por el mismo horizonte sobre el que se apoyaban las letras, la versión de la cadena española sustituyó el fondo oscuro por su rojo corporativo y el blanco limpio del relleno de las letras (corporativo también).

En cuanto al corporativismo de las cadenas, el caso de los logotipos nos da una pista de lo que nos encontraremos. Los logotipos de ABC y Cuatro aparecen en todas las promociones respectivamente $\mathrm{y}$, como hemos visto, también las voces en off se corresponden con las voces corporativas de las cadenas. Sin embargo hay un canal que sobresale en cuanto a la mayor dotación de corporativismo a las piezas promocionales, nos referimos a Cuatro que, gracias al fácil reconocimiento de los colores rojo y blanco posibilita la identificación con el canal y establece una mayor relación entre el producto y la cadena ante los ojos del espectador. Además de los colores, Cuatro hace uso en los anuncios de "Flashforward" de su tipografía corporativa. Esto se puede apreciar tanto en los intertítulos como en los rótulos de texto que indican el horario y día de emisión de la serie.

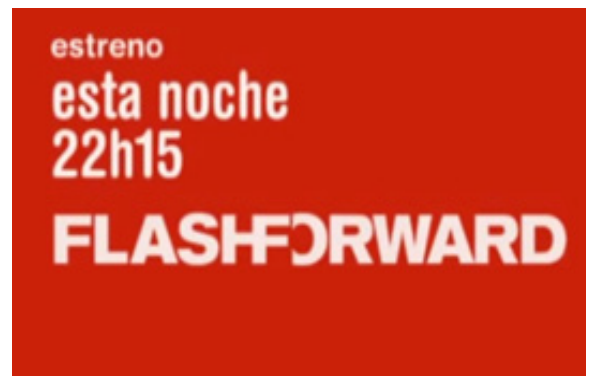

Figura 7. Fotograma de promo de Cuatro.

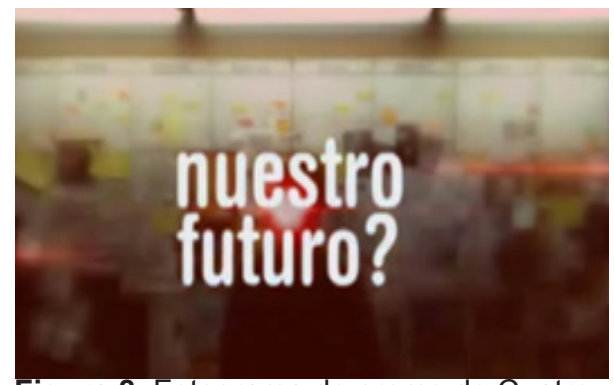

Figura 8. Fotograma de promo de Cuatro.

En el caso norteamericano la preocupación por el corporativismo de la cadena es menos notable. Los colores que predominan en estas promociones son los propios de la I.C. de la serie, blanco y negro. Podemos apreciarlos en las imágenes que aparecen a continuación, en las que además, apreciamos el uso de una tipografía como la del logotipo de la serie en sus versiones mayúscula y

\footnotetext{
${ }^{6}$ En diseño gráfico, contratipo es la utilización sobre fondo negro de una tipografía en color blanco.
} 
Las series como elemento de diferenciación y autopublicidad televisiva.

Análisis comparativo de las promociones de "Flashfoward":

EE.UU (ABC) vs. España (Cuatro)

minúscula. Predominan el uso del contratipo y el relleno blanco de las letras de los textos (corporativismo de la serie, no del canal).

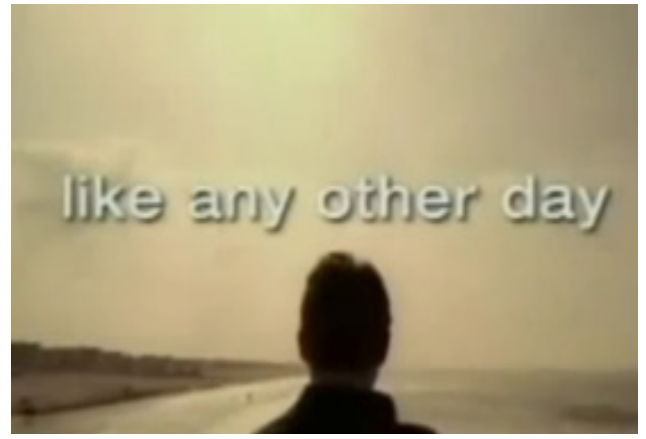

Figura 7. Fotograma de promo de Cuatro.

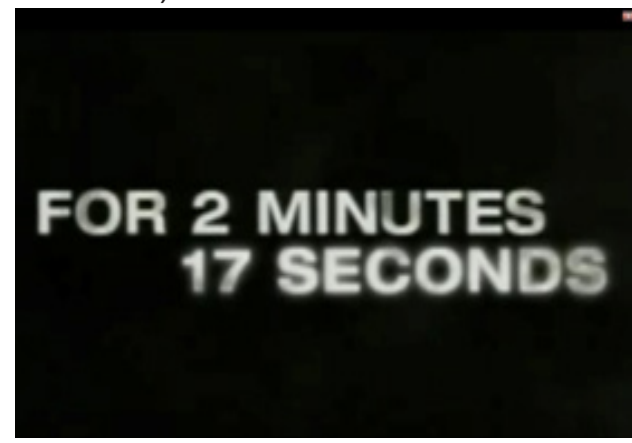

Figura 7. Fotograma de promo de Cuatro.

\subsubsection{Voces en off}

La primera gran diferencia entre las voces en off (que en este caso coinciden con las corporativas del canal), es que una es masculina y otra femenina. Hasta hace pocos años, lo habitual era que las voces corporativas de los canales fuesen masculinas. En España, Cuatro ha sido la primera cadena de televisión generalista que emite en abierto que utilizó una voz femenina como voz corporativa. Esto, por sí solo, ya se constituye como un elemento novedoso, frente a otra cadena que, para promocionar el mismo producto, utiliza una voz masculina. Sin embargo hay ciertos matices que poseen estas voces que las hacen peculiares a ambas. La voz femenina de Cuatro pierde en contundencia y profundidad contra la de ABC, y ésta, a su vez, tiene un timbre menos agradable al oído que la voz española.

Las voces en off son, de los diversos elementos sonoros, los que más connotaciones subjetivas aportan por la capacidad que poseen para transmitir sensaciones, estados de ánimos, generar suspense..., además de favorecer la identificación del producto televisivo con la cadena de una manera más rápida que otros recursos. Esta función de generar suspense o intriga, la cumplen las voces corporativas de Cuatro y $A B C$ en los spots promocionales de "Flashforward". Sin embargo, no son las únicas diferencias que separan las promos de $A B C$ y Cuatro. Adelantábamos que la línea argumental de los anuncios muestra semejanzas así como diferencias, según los aspectos en los que se centra cada anuncio. Nos ocupan ahora las diferencias, que no son más que las diversas muestras de originalidad de cada cadena al desviarse de la presentación de la serie y sus protagonistas.

El principal factor diferenciador, en cuanto a argumento se refiere, radica en el contexto de emisión de la serie: en Estados Unidos, ABC estrena "Flashforward" el 24 de septiembre de 2009 y, en España, Cuatro ${ }^{78}$ lo hace el 6 de octubre del 2009. Es poco frecuente que el intervalo de tiempo entre el estreno en Norteamérica y España sea tan reducido, ya que lo normal es que pasen meses 
hasta que una serie estadounidense se estrene en nuestro país. Cuatro da a conocer en sus promos que emitirá una serie recién estrenada en EE.UU con un gran éxito de audiencia, es decir, ofrece a los espectadores unas credenciales positivas de la serie, otorgándole calidad (avalada por la experiencia americana) al producto televisivo que promociona, a la vez que se da prestigio a sí misma como cadena de televisión por conseguir estrenar esa serie sólo catorce días después que en Norteamérica.

Mencionamos, cuando hablábamos de las semejanzas, que la gran mayoría de las promos (tanto las españolas como las americanas) se centran en realizar la presentación de la serie, los personajes y las diversas tramas secundarias. Sin embargo, no todas las promociones mantienen esta línea. En el caso de ABC hemos analizado un spot en el que no aparecía ninguno de los personajes de la serie, ni se adelantaba argumento alguno. Se trata de un anuncio en el que se suceden cinco breves escenas de lo que serían las visiones del futuro de cinco personas distintas, acompañadas por el intertítulo que usa con frecuencia la cadena americana, "What did you see?". Teniendo en cuenta que esta pieza fue emitida antes del estreno de la serie, genera una gran incógnita al espectador que no conoce el producto, ya que no avanza el motivo del spot ni el contenido promocionado. Sin embargo, la frase del intertítulo se repite en las diferentes promociones de la serie para relacionarlas entre sí y facilitar la comprensión a los espectadores.

En el caso de Cuatro, son dos los anuncios analizados que se desmarcan de la presentación de la serie y personajes de forma "convencional" (tramas y protagonistas). Uno de ellos muestra las grabaciones de diversas cámaras de vigilancia en el momento que se produce el desmayo de la población mundial, adelantando el nombre de la serie y parte del contenido (a diferencia de $A B C$ ) en intertítulos (" ¿ $\mathrm{y}$ si el mundo entero se quedara inconsciente durante dos minutos y diecisiete segundos?"). El segundo anuncio del que hablamos, contiene una alta carga de corporativismo, con múltiples elementos gráficos de Cuatro, que se introducen al inicio y al final de la promoción, otorgando a la serie una identificación inmediata con el canal. Así, "Flashforward" se integra entre los diversos programas y series de la cadena, como uno más.

\subsection{Tipología de promociones de "Flashforward" en los canales ABC y Cuatro}

A continuación, estableceremos un esquema sobre la tipología de piezas promocionales de "Flashforward" que hemos encontrado en el análisis:

1. Promociones de presentación. Puesto que se trata del estreno de una nueva serie de televisión resulta prácticamente obligatorio la realización de

\footnotetext{
${ }^{7}$ Recordemos que la serie ya se había estrenado en España un día antes (5 de octubre de 2009), en el canal temático y de pago, AXN.
} 
Las series como elemento de diferenciación y autopublicidad televisiva. Análisis comparativo de las promociones de "Flashfoward":

EE.UU (ABC) vs. España (Cuatro)

una presentación de la serie: adelanto de la trama principal, protagonistas principales y tramas y personajes secundarios, así como género de la serie. Este tipo de promociones cuentan con una doble vertiente de reacción según el efecto que puedan provocar en el espectador: por un lado, el argumento de la serie puede atraer a la audiencia, sin embargo, el hecho de transmitir que es de acción, intriga y con tintes de ficción, ya resultan motivos suficientes de rechazo para un target al que no le atrae este tipo de contenidos y realización.

2. Presentación "amoldada" a la cadena. Decimos amoldada porque este tipo de spots tienen una alta carga de corporativismo, restándole protagonismo a la propia promoción de la serie.

3. Promociones de trama única. Éstas también pueden ser consideradas de presentación, pero la diferencia radica en que se centran en un solo aspecto del argumento de la serie: puede ser la historia personal de un personaje, cómo un mismo acontecimiento afecta de diversas formas a los protagonistas, tramas romántico-amorosas...

4. Creatividad propia. Lo habitual en la promoción de series de televisión es la utilización de fragmentos de escenas de las mismas. El simple hecho de no incluir ninguna escena en una promo ya se puede considerar original. Estas piezas están formadas por diversos elementos que guardan relación con la trama de la serie, aunque el espectador no sea consciente de ello. Este tipo de promociones tienen la función de provocar intriga en el espectador y no necesariamente se resuelven en el propio anuncio, sino que completan su significado con el resto de promos de la campaña promocional.

5. Promoción de dos series en una promo. Hemos analizado un ejemplo en las dos cadenas de televisión que nos ocupan, de cómo aprovechar una serie de éxito para dar a conocer otra nueva. ABC lo hizo con "Grey's Anatomy", y Cuatro con "Perdidos". De esta manera, se llama la atención del espectador con la serie que funciona bien y se introduce la serie, todavía desconocida, y que se encuentra en la fase de promoción, con el objetivo de favorecer un trasvase de audiencias de la serie veterana a la nueva.

\subsection{Cómo elaborar promociones de series de televisión (de estreno)}

Tras la realización del análisis comparativo de las promos de "Flashforward" en los canales $A B C$ y Cuatro, se ha elaborado una propuesta de guía o recomendaciones a la hora de realizar piezas promocionales de series de televisión. A continuación, expondremos pautas, advirtiendo de antemano que lógicamente cada serie y su canal de emisión correspondiente poseen sus propias especificidades que no se pueden contemplar en este punto, pero que, sin duda, han de ser consideradas. 
Una campaña promocional de una serie que va a ser estrenada por primera vez en televisión debe contar, entre sus piezas publicitarias, con al menos tres tipos de promos:

1. Piezas de presentación. Aquellos spots en los que se avanza la trama principal de la serie, así como sus protagonistas principales. Una contextualización de la serie.

2. Piezas de trama única. Éstas pueden centrarse en la trama principal o bien en una de las secundarias. Dar pinceladas de las historias paralelas que se suceden en la serie permite ofrecer al espectador nuevos puntos de vista.

3. Piezas de creatividad propia. Estas piezas se refieren a todas aquellas promos realizadas con el sello personal de la cadena emisora que pueden contener elementos no identificables con la serie para crear un halo de intriga sobre ese producto televisivo promocionado. Este tipo de promociones suelen quedar resueltas por nuevas piezas que las completan.

Además de introducir al espectador en la historia, las promos de una serie de estreno deben destacar a los personajes principales y a los secundarios más importantes (aunque no sea por igual), para intentar captar a un público más heterogéneo que se pueda sentir más identificado con los papeles secundarios que con los principales. Así se cubriría un radio más extenso de público potencial.

Una moderada presencia de elementos corporativos del canal de televisión emisor favorece, como ya hemos mencionado, la identificación del producto televisivo con la cadena. Consideramos que con tres aspectos sería suficiente: colores, tipografía y voz en off corporativos. Los colores y la tipografía de la cadena son más apreciados en sobreimpresiones textuales e intertítulos.

Relacionado con la recomendación anterior y la identificación del canal y la serie, es apropiado que en una campaña promocional de estreno (incluso sin ser de estreno, sino de continuación) se incluya alguna pieza que vamos a denominar "cara a cara entre la serie y la cadena". Ésta sería un montaje en el que el protagonismo del spot se repartiría al $50 \%$ entre la cadena y la serie. Cuatro, ha empleado esta técnica para promocionar series como "House", en las que, tomando diversos diálogos de la serie, el personaje cuenta una historia respaldada por la voz en off de la cadena, relacionando la serie con el propio canal. Otra versión de esta modalidad sería lo que hizo la cadena $A B C$ en la campaña promocional de sus series en el año 2009 y que hemos analizado en el estudio de caso: la grabación de piezas promocionales con los protagonistas de diversas series en el mismo anuncio, con un tono cómico y desenfadado, que suelen resultar atractivas al espectador habitual de las series.

Estas ideas para la elaboración de piezas y su posterior calendarización en parrillas televisivas han nacido de los pros y contras detectados en el trabajo promocional de $A B C$ y Cuatro. Los aciertos de las piezas, los elementos bien potenciados y que cumplen la función promocional suscitando el interés, son los 
Las series como elemento de diferenciación y autopublicidad televisiva. Análisis comparativo de las promociones de "Flashfoward":

EE.UU (ABC) vs. España (Cuatro)

que nos dan las pautas del trabajo correcto. Los contras, las carencias halladas, son los que deben observarse para evitar su uso en los trabajos que son parte de la identidad de canal.

\section{CONCLUSIONES}

La mayor incógnita que puede surgir en el estudio comparativo de las piezas promocionales de "Flashforward" en ABC y Cuatro es acerca de su similitud: ¿EI hecho de promocionar el mismo producto televisivo hace que las promociones de los dos canales sean similares? Por un lado, aunque se trate de la promoción del mismo producto existen notables diferencias que permiten que podamos afirmar que cada cadena de televisión (ABC y Cuatro) posee su estilo propio en los spots promocionales de la serie.

Sin embargo, las semejanzas entre las piezas de los dos países son evidentes. Nos encontramos en un caso en el que los aspectos similares y los creados por el canal tienen su presencia a partes iguales en las promos de "Flashforward" de Cuatro y ABC. Una parte "impuesta" u obligada, condicionada por el producto en sí, y la parte "ideada" por el propio canal, que se refiere, sobre todo, a los elementos corporativos y creativos del mismo. En cierta manera, la proyección de la I.C. es otra imposición, ya que sus usos vienen marcados por el Manual de Identidad Corporativa de la cadena. Por lo tanto, nos quedarían los aspectos creativos como el único elemento verdaderamente diferenciador de las promos de $A B C$ y Cuatro.

Una vez concluido el análisis, podemos afirmar que la cadena estadounidense $A B C$ centra sus promociones en la serie, dejando prácticamente al margen la promoción de canal. Los elementos de la I.C. únicamente se aprecian en la voz corporativa (voz en off) y el logotipo de la cadena. Los anuncios se componen, exclusivamente, de escenas de la serie, pudiendo provocar una sensación de repetición al visionarlos uno tras otro.

La inmensa mayoría de las promociones de $\mathrm{ABC}$ comparten el mismo eslogan: "What did you see?", esto permite la identificación de todas las piezas como parte de la misma campaña y ayuda al espectador a entender el mensaje promocional. Las promociones de la cadena española están marcadas por la gran cantidad de aspectos corporativos que incluyen las promociones. El simple hecho de poner los intertítulos en la tipografía de Cuatro marca la diferencia con el estilo de ABC: la serie se identifica como parte del canal y se integra en sus contenidos. Así, el estilo promocional de la cadena española se ve más marcado, más perceptible en todas las promos.

Otra de las grandes y significativas diferencias con el canal americano, y que proporciona una gran singularidad a las piezas españolas, es el hecho de

\footnotetext{
"¿QQué has visto?”.
} 
que el estreno de la serie en España fuese tan sólo unos días después que en EE.UU., ya que esto ha permitido a Cuatro promocionar no sólo la serie, sino la rapidez de la emisión en nuestro país otorgando prestigio a la propia cadena. Algo similar a lo que hizo ABC en la promoción de "Flashforward", explotando que es una serie de los creadores de la exitosa "Lost" y persiguiendo el objetivo de generar prestigio.

Las piezas promocionales suelen mantener en todos los canales la duración de un spot convencional (15", 20" y 30"). En el análisis de nuestro objeto de estudio descubrimos que el tiempo de los spots promocionales puede llegar al minuto de duración. Estas piezas largas también son adaptadas a la duración de los spots convencionales, reduciendo las imágenes mostradas, aunque perdiendo un ápice de lo transmitido en las versiones extendidas.

No cabe duda de la importancia que ha ido adquiriendo la promoción de contenidos por parte de los canales de televisión. Se ha ampliado el número de piezas promocionales, su duración (desde ráfagas de cinco segundos hasta versiones extendidas de un minuto), han dado un salto creativo... Podemos hablar de que cada cadena cuenta con un estilo propio a la hora de elaborar sus autopromociones y que esa estética suele mantenerse a lo largo de un tiempo. Sin embargo, dependiendo del contenido promocionado, esa concepción creativa puede verse alterada, condicionada por las características propias de los productos televisivos. Así, en el caso de Cuatro con "Flashforward", las autopromociones han tenido un marcado carácter de acción, que de otra manera no hubiera sido el elemento principal de las promos de la cadena española.

En este caso concreto de "Flashforward" no podemos definir el tiempo como un factor que establezca una posible copia de Cuatro a ABC. La propia temática condiciona demasiado las similitudes entre las promos de los dos canales, eso es inevitable. Por lo tanto, el parecido entre las piezas no debe considerarse como una copia, sino como el resultado de la aplicación de la misma línea promocional: dar a conocer la serie con el argumento, personajes principales y tramas secundarias. El caso de "Flashforward", al tratarse de una serie nueva, tiene esta peculiaridad.

Planteábamos al inicio de la investigación que las promociones de series de televisión tienen un alto contenido corporativo e identificativo con el canal emisor. Sin embargo, esta hipótesis no se corrobora del mismo modo en las dos cadenas. Podemos afirmar que resulta más verídica en el caso de Cuatro. Confirmamos esta aseveración en el análisis comparativo, en el que comprobamos que la cadena española aplica su corporativismo en las promos en dosis superiores que $A B C$. Hemos cotejado, también, que basta únicamente con mostrar la tipografía o un color corporativo de la cadena de televisión para que se haga efectiva la identificación del canal con la serie. El esquema habitual de reproducción de los elementos corporativos en las piezas promocionales de "Flashforward", sobre todo en Cuatro más que $A B C$, es el siguiente: 
140 Las series como elemento de diferenciación y autopublicidad televisiva. Análisis comparativo de las promociones de "Flashfoward":

EE.UU (ABC) vs. España (Cuatro)

1. Breve identificación de la cadena, en los primeros segundos de la pro mo: logo, colores...

2. Utilización de la tipografía y colores corporativos en intertítulos, sobreim presiones así como voz en off en el desarrollo de la pieza.

3. Cierre con el logotipo de la cadena, junto con el día y hora de emisión de la serie.

Este esquema es el que encontramos tras realizar el análisis de los spots promocionales de "Flashforward" de Cuatro y ABC, siendo más utilizados en la cadena española que en la americana.

Sobre la creatividad en las piezas promocionales de la serie, y la suposición inicial de que está ligada a la temática de la misma, en el caso de "Flashforward", cuyo guión es tan específico, se refleja en el eje argumental de todas las piezas de la campaña, por encima de la promoción de canal. Sin embargo, conviene establecer de nuevo la diferencia entre $A B C$ y Cuatro por la mayor presencia de aspectos corporativos de la cadena española y, que permiten reflejar finalmente, su identidad de marca (de canal, en este caso). No obstante, y como hemos propuesto en los consejos a la hora de elaborar piezas promocionales para series de televisión, la creatividad se refleja hasta en los más pequeños detalles. Nos referimos a esas promociones que, a priori, no tienen que ver con el argumento de la serie o no muestran los aspectos identificativos de la misma, pero crean una metáfora o una referencia a la serie con elementos que se relacionan con la temática. Estas piezas corren el riesgo de no ser entendidas y de caer en el olvido para el espectador, pero cuando son captadas, cumplen su función promocional a la perfección y permanecen en el recuerdo de la audiencia con más facilidad.

Este estudio demuestra la importancia que ha adquirido la promoción de contenidos para las cadenas de televisión. Las piezas audiovisuales están cuidadas y trabajadas para provocar una reacción en el espectador $y$, al fin y al cabo, diferenciarse por medio de sus contenidos, de la amplia oferta de canales existentes e incluso de las nuevas formas de consumo de productos seriados que ofrece Internet.

Movidos por las nuevas tendencias, los canales de televisión han provocado que la promoción de contenidos en televisión haya ganado en inmediatez (cuando hasta no hace mucho tiempo, los productos televisivos norteamericanos tardaban incluso meses en cruzar "el charco"), en calidad (la complejidad audiovisual de las piezas promocionales va más allá de la mera selección de escenas) y en originalidad, promocionando una serie de televisión sin mostrar imagen alguna de la misma.

Finalmente, esta investigación permitió un conocimiento más profundo de los mecanismos publicitarios de los canales para poder fidelizar a sus audiencias con nuevos productos seriados. 


\section{REFERENCIAS BIBLIOGRÁFICAS}

(2003) La muerte del spot clásico de televisión. Marketingdirecto.com [en línea]. [Consulta 21 enero 2010]. <http://www.marketingdirecto.com/actualidad/publicidad/la-muerte-del-spotclasico-de-television/>

(2004) La televisión generalista: ¿cada vez menos 'generalista'? Marketingdirecto.com, [en línea]. [Consulta 25 noviembre 2009]. <http://www.marketingdirecto.com/noticias/noticia. php? idnoticia $=11154 \&$ titular=LA\%20TELEVISI\%C3\%93N\%20GENERALISTA:\%20\%C2\%BFCADA\%20VEZ\%20MENOS\%20'GENERALISTA>

AAKER, David (2005) Liderazgo de marca. Barcelona: Deusto.

BARKER, C. (1999): Television, Globalization and Cultural Identities. Filadelfia, Open University Press.

BARROSO GARCÍA, Jaime (2002): Realización de los géneros televisivos. Madrid: Editorial Síntesis.

CASTAÑO RIVERO, V. J.; GÁNDARA GIL, L. M; MARTÍNEZ GONZÁLEZ, F.; MARTÍNEZ MARTÍNEZ, F.; SALVADORES SERRANO, B.: Las autopromociones de Telemadrid. Universidad Complutense de Madrid [en línea]. [Consulta: 1 octubre 2009]. <http://www.ucm. es/info/multidoc/multidoc/revista/cuad6-7/anexo/promos_telemadrid/promotm3.htm>

CEBRIÁN HERREROS, Mariano (2004) Modelos de televisión: generalista, temática y convergente con Internet. Barcelona: Paidós Ibérica.

COSTA, Joan (1992a): Identidad corporativa y estrategia de empresa. 25 casos prácticos. Barcelona: CEAC.

FERNÁNDEZ, Á. (2009): A más canales, más contenidos y... ¿más baratos? El Mundo.es [en línea]. [Consulta 28 de diciembre 2009]. <http://www.elmundo.es/elmundo/2009/12/28/ comunicacion/1261989188.html>

GONZÁLEZ OÑATE, C. (2006): La continuidad televisiva en la era digital. Nuevos discursos publicitarios de expresión de Identidad Corporativa. El nacimiento de Cuatro. Tesis Doctoral, Universidad Jaume I.

GONZÁLEZ OÑATE, C.; LÓPEZ FONT, L.: El posicionamiento en 20": las autopromociones de las cadenas de televisión. Comunicar [en línea]. [Consulta 1 octubre 2009]. <: http:// dialnet.unirioja.es/servlet/articulo?codigo=2925997>

JABONERO, D. (2009): La guillotina de las series. El Mundo [en línea]. [Consulta 1 diciembre 2009]. <http://www.elmundo.es/elmundo/2009/12/01/television/1259655866.html>

KELLER, Kevin (2008) Administración estratégica de marca. México: Pearson.

ORTEGA MARTÍNEZ, Enrique (1992) La publicidad en televisión. Madrid: Mundi-Prensa.

PIÑA, R. (2009): 2010: llega una nueva televisión. El Mundo [en línea]. [Consulta 29 diciembre 2009]. <http://www.elmundo.es/elmundo/2009/12/25/comunicacion/1261770316.html>

RIBÉS, M.: La publicidad en televisión. El spot en segundo plano. Universidad Jaume I [en línea]. [Consulta 1 octubre 2009]. <http://www.uji.es/bin/publ/edicions/jfi11/16.pdf>

SABORIT, José (2000) La imagen publicitaria en televisión. Madrid: Cátedra.

SANZ DE LA TAJADA, Luis Ángel (1994) Integración de la identidad y la imagen de la 
142 Las series como elemento de diferenciación y autopublicidad televisiva. Análisis comparativo de las promociones de "Flashfoward":

EE.UU (ABC) vs. España (Cuatro)

empresa. Desarrollo conceptual y aplicación práctica. Madrid: Editorial Esic.

SEMPRINI, Andrea (1995) El marketing de la marca. Una aproximación semiótica. Barcelona: Paidós.

VALDERRAMA SANTOMÉ, M. (2005) De la paleo a la neotv a través de la autopromoción y la identidad televisiva: El caso de TVG. Área Abierta n¹0 [en línea]. [Consulta 20 octubre 2009]. <http://www.ucm.es/info/cavp1/Area\%20Abierta/10\%20Area\%20Abierta/ articulos/Valderrama.pdf>

VALDERRAMA SANTOMÉ, M. (2008) A publicidade televisiva en Galicia. Análise dos emisores, soportes e tendencias creativas [1960 - 2000]. Santiago de Compostela: Xunta de Galicia.

\section{Páginas web}

Página web de ABC: <http://abc.go.com/> [Consultada frecuentemente entre octubre de 2009 y junio de 2010].

Página web de Cuatro: <http://www.cuatro.com> [Consultada frecuentemente entre octubre de 2009 y junio de 2010].

ABC Logo: <http://www.marketingshift.com/resources/abc-logo.jpg> [Consultada 12 diciembre 2009].

Cuatro Logo: <http://www.terra.es/personal9/avertigo/logo_cuatro_web.jpg> [Consultada 12 diciembre 2009].

Flashforward TV: <http://flashforwardtv.com/> [Consultada frecuentemente entre octubre de 2009 y junio de 2010].

Fórmula TV: <http://www.formulatv.com> [Consultada frecuentemente entre octubre de 2009 y junio de 2010].

Ley 7/2010, de 31 de marzo, General de la Comunicación Audiovisual: <http://www.boe. es/boe/dias/2010/04/01/pdfs/BOE-A-2010-5292.pdf>

POLO, Juan: Diccionario Teléfilo: Contraprogramación: <http://www.vayatele.com/diccionario/diccionario-telefilo-contraprogramacion>

Tele Digital y Satélite Infos: <http://www.sateliteinfos.com/edito/arquivos.asp/edito/22/tv-tematica-versus-tv-generalista.html> [Consultada 12 diciembre 2009].

TV by the Numbers: <http://tvbythenumbers.com/> [Consultada 26 octubre 2009].

Vaya Tele: <http://www.vayatele.com> [Consultada frecuentemente entre octubre de 2009 y junio de 2010].

Vertele: <http://www.vertele.com> [Consultada frecuentemente entre octubre de 2009 y junio de 2010].

Wikipedia: <http://en.wikipedia.org/wiki/Television_content_rating_systems>

Wikipedia: <http://en.wikipedia.org/wiki/TV_Parental_Guidelines>

Wordlingo: <http://www.worldlingo.com/ma/enwiki/es/American_Broadcasting_Company> [Consultada 24 octubre 2010]. 


\section{Breve semblanza biográfica de las autoras}

Nuria Costas Fontán es Licenciada en Publicidad y Relaciones Públicas por la Universidad de Vigo y, actualmente, doctoranda en periodo de realización de la Tesis Doctoral en la misma Universidad.

Mónica Valderrama Santomé es Profesora del Área de Comunicación Audiovisual y Publicidad de la Universidad de Vigo. Licenciada en Periodismo por la Universidad de Santiago de Compostela y en Publicidad y RR.PP. por la Universidad de Vigo. Doctora en Publicidad y RR.PP. por la Universidad de Vigo y Premio Extraordinario Doctorado.

(Recibido el 13-05-2011; aceptado el 28-12-2011) 